\title{
A construção de um território de desenvolvimento rural: recursos $e$ ativos territoriais específicos ${ }^{1}$
}

\author{
Ademir Antonio Cazella \\ Universidade Federal de Santa Catarina - Florianópolis - Santa Catarina - Brasil \\ Leandro Guimarães Nunes de Paula \\ Universidade Federal de Santa Catarina - Florianópolis - Santa Catarina - Brasil \\ Monique Medeiros \\ Universidade Federal do Pará - Belém - Pará- Brasil \\ Valério Alécio Turnes \\ Universidade do Estado de Santa Catarina - Florianópolis - Santa Catarina - \\ Brasil
}

\begin{abstract}
Resumo
Este artigo tem por objetivo identificar os recursos e ativos territoriais específicos da Serra Catarinense que possam constituir uma oferta compósita no processo de formação de uma Cesta de Bens e Serviços Territoriais (CBST). Para tanto, parte-se da realidade do território da Serra Catarinense, em especial no que se refere a um levantamento preliminar desses tipos de recursos e ativos territoriais, capazes de catalisar ações de desenvolvimento que desviam do modelo produtivista hegemônico. A abordagem em questão coloca em destaque a importância nos processos de desenvolvimento territorial da articulação entre distintas iniciativas de valorização de produtos e serviços específicos. Por meio de pesquisas bibliográfica e documental, bem como do trabalho de campo na Serra Catarinense, esta investigação aponta que a abordagem de CBST se apresenta como um aporte teóricometodológico inovador para a compreensão das novas definições e ressignificações de ações de desenvolvimento em espaços rurais no Brasil. No contexto empírico analisado, para além das iniciativas de criação de Indicações Geográficas (IG) para o queijo artesanal serrano, maçã, vinhos de altitude e o mel de melato, o turismo rural evidencia as potencialidades do território no desenvolvimento de iniciativas que consolidem uma CBST.
\end{abstract}

Palavras-chave: Desenvolvimento Territorial. Cesta de bens e serviços territoriais. Recursos territoriais.

\footnotetext{
${ }^{1}$ A elaboração deste artigo baseia-se em temas desenvolvidos pelo segundo autor na dissertação de mestrado, em andamento, junto ao Programas de Pós-Graduação em Agroecossistemas, da Universidade Federal de Santa Catarina. A primeira versão do artigo foi publicada nos anais da The Third International Conference "Agriculture and Food in na Urbanizing Society", realizada em Porto Alegre, entre 17 e 21 de setembro de 2018.
} 


\title{
The construction of a rural development territory: specific territorial resources and assets
}

\begin{abstract}
This article aims to identify the specific resources and territorial assets of the Santa Catarina Sierra that may constitute a composite offer in the process of forming a Basket of Territorial Goods and Services (CBST). To this end, we start from the reality of the territory of the Santa Catarina Mountains, especially with regard to a preliminary survey of these types of resources and territorial assets, capable of catalyzing developmental actions that deviate from the hegemonic productivist model. This approach emphasizes the importance in the territorial development processes of the articulation between different initiatives of valorization of specific products and services. Through bibliographic and documentary research, as well as fieldwork in Serra Catarinense, this research points out that the CBST approach presents itself as an innovative theoretical-methodological approach to the understanding of new definitions and resignifications of development actions in rural spaces. in Brazil. In the empirical context analyzed, in addition to the initiatives of creation of Geographical Indications (GI) for artisan serrano cheese, apple, wines of altitude and melato honey, rural tourism highlights the potential of the territory in the development of initiatives that consolidate a CBST.
\end{abstract}

Keywords: Territorial Development. Basket of territorial goods and services. Territorial resources.

\section{La construcción de un territorio de desarrollo rural: recursos y activos territoriales específicos}

\section{Resumen}

Este artículo tiene como objetivo identificar los recursos específicos y los activos territoriales de la Sierra de Santa Catarina que pueden constituir una oferta compuesta en el proceso de formación de una Cesta de Bienes y Servicios Territoriales (CBST). Para ello, partimos de la realidad del territorio de las montañas de Santa Catarina, especialmente con respecto a un estudio preliminar de este tipo de recursos y activos territoriales, capaces de catalizar acciones de desarrollo que se desvían del modelo productivista hegemónico. Este enfoque enfatiza la importancia en los procesos de desarrollo territorial de la articulación entre diferentes iniciativas de valorización de productos y servicios específicos. A través de la investigación bibliográfica y documental, así como el trabajo de campo en Serra Catarinense, esta investigación señala que el enfoque CBST se presenta como un enfoque innovador teórico-metodológico para la comprensión de nuevas definiciones y resignificaciones de acciones de desarrollo en espacios rurales. en Brasil. En el contexto empírico analizado, además de las iniciativas de creación de Indicaciones Geográficas (IG) para el queso serrano artesanal, la manzana, los vinos de altitud y la miel de melato, el turismo rural destaca el potencial del territorio en el desarrollo de iniciativas que consoliden un CBST.

Palabras clave: Desarrollo Territorial. Cesta de bienes y servicios territoriales. Recursos territoriales.

\section{Introdução}

Com o crescente processo de globalização, sobretudo da economia, houve a marginalização de vários territórios rurais. O enfoque teórico-metodológico da Cesta de Bens e Serviços Territoriais (CBST), elaborado por uma equipe de pesquisadores da Université Pierre Mendes de Grenoble (França), coloca no centro do processo de 
desenvolvimento territorial os produtos e serviços de qualidade associados a características peculiares de determinados territórios, a maioria deles marginalizados, até então, pelos processos de desenvolvimento hegemônico. As primeiras evidências de pesquisa em territórios franceses demonstraram que a valorização dos chamados recursos territoriais específicos representa o principal eixo norteador de ações de desenvolvimento territorial em zonas rurais. Dentre outros pontos, a ação combinada de diferentes atores sociais é fundamental para iniciar e manter no tempo o processo de especificação ou valorização de produtos e serviços característicos de um território (PECQUEUR, 2005; MOLLARD; PECQUEUR, 2007).

Entendendo a pertinência da mobilização desses preceitos teóricos para estudar outras situações empíricas que não as francesas, este artigo tem por objetivo discutir a pertinência dos conceitos correlacionados à CBST para a implementação de iniciativas brasileiras de desenvolvimento territorial. Segundo Campagne e Pecqueur (2014), essa abordagem se adequa e se torna mais efetiva quando aplicada em zonas rurais desfavorecidas, contribuindo para a territorialização desse tipo de espaço. Em relação à realidade brasileira, esta análise se justifica, de um lado, pela incipiente produção científica associada a essa abordagem e, de outro lado, pela relativa abundância de estudos que evocam o desenvolvimento territorial de forma genérica e desprovido de referencial teórico-metodológico.

Para tanto, este trabalho mobiliza a abordagem da CBST para compreender os processos territoriais em curso no contexto da Serra Catarinense. Nesse cenário, existem ações coletivas de atores territoriais associadas a produtos e serviços específicos, a exemplo da maçã, vinho de altitude, queijo artesanal serrano, mel de melato de bracatinga, pinhão, carne bovina frescal e goiaba serrana ${ }^{2}$, além do artesanato de vime e do turismo rural. Tendo em vista os propósitos deste estudo, o queijo artesanal serrano, a maçã, o vinho de altitude e o mel de melato, produtos que apresentam maior importância socioeconômica no contexto do território da Serra Catarinense, com iniciativas em curso relacionadas à obtenção de Indicações Geográficas (IG)33, bem como o turismo rural, foram considerados importantes componentes de uma possível CBST e, portanto, priorizados na análise.

Os resultados aqui analisados foram formulados a partir de pesquisa bibliográfica e documental, além de observações participantes e 49 entrevistas semiestruturadas, realizadas entre abril e maio de 2018, junto a atores públicos, associativos e privados da Serra Catarinense. Desse total de entrevistas quatorze foram realizadas com atores públicos e 35 com atores privados. Dentre os atores privados, 28 eram, também, representantes associativos. Para restringir o número de

\footnotetext{
${ }^{2}$ A carne tipo frescal remonta ao período do tropeirismo do Século XIX. O método de preparo consiste numa forma de conservar a carne com o uso de sal, porém em menor quantidade quando comparado ao charque. Já a goiaba serrana, conhecida também por feijoa, é uma planta frutífera da região sul do Brasil. O seu fruto tem um sabor muito peculiar, harmonizando acidez e doçura ao mesmo tempo. Além disso, esse tipo de goiaba possui uma grande concentração de vitamina $C$ e flavonoides, tornando-a um excelente alimento preventivo de doenças.

3 Uma IG visa valorizar produtos e serviços que apresentam algum tipo de especificidade ou originalidade por meio de um signo de qualidade. Trata-se de uma tradição em países europeus, notadamente França, Espanha, Portugal e Itália, instituída no Brasil há pouco mais de 20 anos por meio da Lei de Propriedade Industrial. O Instituto Nacional de Propriedade Industrial é o órgão responsável pela avaliação e reconhecimento dos pedidos de IG.
} 
entrevistas foi utilizada a técnica de saturação amostral, determinada pelo momento em que o trabalho de campo não apresenta dados ou esclarecimentos novos sobre o objeto estudado (FONTANELLA et al., 2011).

A fundamentação teórico-metodológica que guia as análises desses resultados, bem como as análises propriamente ditas, estão organizadas em três partes principais. A primeira apresenta uma síntese da abordagem teóricometodológica da CBST, com destaque para a noção de recurso e ativo territorial específico. A segunda discute a aplicação empírica desse enfoque na região serrana de Santa Catarina, enfatizando as iniciativas territoriais de valorização de serviços e produtos específicos. $\mathrm{E}$ a terceira traz as considerações finais, evidenciando que o território da Serra Catarinense apresenta condições de base (cenário, governança territorial, e produtos e serviços específicos) para catalisar um processo de desenvolvimento territorial a partir de ativos territoriais específicos. Destaca-se, ainda, que é preciso aprimorar o sistema de governança territorial e o estabelecimento de sinergias entre as iniciativas em marcha.

\section{Cesta de Bens e Serviços Territoriais: um olhar sobre os recursos territoriais específicos}

O conceito de território adotado neste artigo está associado à perspectiva de construção social por parte de atores mobilizados para resolver problemas comuns ou compartilhados. Essa perspectiva concebe a valorização socioeconômica de produtos e serviços a partir da identificação de inputs territoriais existentes na forma de recursos e ativos (PECQUEUR, 2001; 2005). Entende-se por ativos aqueles fatores que estão "em atividade", enquanto que os recursos ainda não foram explorados, mas podem ser revelados ou valorizados. Diferentemente dos ativos, os recursos representam uma reserva, um potencial latente ou virtual a ser ativado (HIRCZAK et al., 2008a).

Uma das principais características desse estilo de desenvolvimento consiste em transformar recursos territoriais em ativos, por meio da valorização ou especificação desses primeiros nos mercados locais e regionais. Essa característica do desenvolvimento territorial pressupõe que os recursos territoriais latentes são inseridos nos mercados a partir da ação coletiva de atores sociais interessados na sua revelação (BENKO; PECQUEUR, 2001).

Colletis e Pecqueur (2005) diferenciam ativos e recursos territoriais genéricos daqueles considerados específicos. Os ativos e os recursos genéricos são determinados de acordo com seu valor ou o seu potencial. $O$ atributo genérico independe do processo de produção e do "gênio ou cultura do lugar" onde é produzido. Assim, esse tipo de ativo ou recurso é transferível para outros territórios, tendo como local de troca o mercado. De forma mais didática, pode-se estabelecer uma analogia dos recursos e ativos genéricos com a mão de obra. Os recursos genéricos correspondem à mão de obra não qualificada, que não está sendo utilizada e não muda a sua natureza ao se transformar em um ativo genérico, pois continua não qualificada, mas passa a ser utilizada e adquire um valor econômico.

Os ativos específicos, por sua vez, têm um caráter diferente dos genéricos, dado que a sua valorização está associada à sua condição de uso. Enquanto um ativo genérico é totalmente transferível, um ativo específico implica em um custo de 
transferência relativamente alto e irrecuperável. Esse tipo de ativo é intransferível, pois é o resultado de um processo que envolve diversos atores sociais e características específicas ou únicas. Esses ativos são construídos a partir de processos interativos e cognitivos de atores dotados de diferentes competências que, ao se articularem, produzem novos conhecimentos (BENKO; PECQUEUR, 2001).

Os ativos genéricos são incapazes de diferenciar um território de outro, uma vez que são susceptíveis a transferências e encontrados em diversos lugares. Para se obter uma diferenciação durável em comparação a outros territórios, torna-se necessário que os recursos e ativos não sofram ameaças de transferências. O que permite essa condição é o caráter de especificidade associado ao território de origem (PECQUEUR, 2005). O Quadro 1 abaixo sintetiza as principais diferenças entre recursos e ativos e suas características genérica ou específica.

Quadro 1. Tipologia dos recursos territoriais

\begin{tabular}{|c|c|c|}
\hline Categorias & Genérico & Específico \\
\hline Recurso & $\begin{array}{c}\text { Fatores de localização não utilizados, } \\
\text { discriminados por preço e custo de } \\
\text { transporte (cálculo, otimização). }\end{array}$ & $\begin{array}{c}\text { Fatores imensuráveis e intransferíveis cujo } \\
\text { valor depende da organização que os cria. }\end{array}$ \\
\hline Ativo & $\begin{array}{c}\text { Fatores de localização não utilizados, } \\
\text { discriminados por preço e custo de } \\
\text { transporte (cálculo, otimização). } \\
\text { - Pode ser ativado em qualquer território. }\end{array}$ & $\begin{array}{c}\text { Fator comparável cujo valor está } \\
\text { relacionado a um uso específico: } \\
\text { - Custo de irreversibilidade; }\end{array}$ \\
\hline
\end{tabular}

Fonte: Adaptado de Benko; Pecqueur (2001).

Como é possível perceber, um dos primeiros desafios do desenvolvimento territorial recai sobre a identificação de recursos específicos. Na sequência, torna-se necessário acionar um processo de especificação ou ativação de recursos. Ou seja, os recursos específicos merecem uma atenção maior, pois neles reside a possibilidade de construção de produtos e serviços com características enraizadas no território (PECQUEUR, 2005). Sobre esse tema, Requier-Desjardins (2013) considera que a ativação de recursos específicos representa um processo de transformação, que resulta da ação coletiva de um conjunto de atores ancorados territorialmente.

Em outros termos, o recurso específico, ao se tornar ativo, é transformado pelo sistema de produção, por meio de um novo sistema de normas, mudando de natureza. No estágio da virtualidade, tudo pode ser potencialmente recurso, mas nem tudo pode se tornar automaticamente um ativo, uma vez que as condições da metamorfose não estão no objeto/recurso, mas nas estratégias adotadas pelos atores no processo de produção (PECQUEUR, 2005).

Portanto, o processo de identificação e valorização de recursos é sempre proposital, mesmo quando a criação de determinados recursos não seja premeditada. O recurso territorial específico está atrelado a uma característica de um território, que tem como base a ação humana (intencional e não-intencional) concebida como um fator indutor do processo de produção. Os ativos territoriais 
específicos têm, em sua gênese, unicamente a atividade intencional humana, sendo então resultantes das estratégias dos atores sociais (MOLLARD, 2001). Para Carrière e Cazella (2006), a metamorfose de recursos em ativos específicos é inseparável da história e da memória social de aprendizagem coletiva característica do território.

A transformação de recurso em ativo específico induz a geração de conhecimentos próprios do território. Quanto maior o conhecimento acumulado acerca de um território, maiores as possibilidades de consolidação dessa transformação. Além disso, mais facilmente estratégias duradouras de desenvolvimento são construídas em zonas rurais. No entanto, esse processo exige a aproximação entre atores internos e externos ao território, formando redes institucionais que possibilitem a troca de informações e a transformação de recursos em ativos territoriais (PERRON; JANIN, 2014).

\begin{abstract}
O importante é a proposição de ferramentas para analisar, compreender, gerenciar essa transição. É uma questão de "ativar", de valorizar recursos, muitas vezes, simplesmente potenciais e latentes, para fazer deles, através do exercício da cognição, aprendizagem e de troca, ativos específicos susceptíveis de gerar rendas de diferenciação a serem valorizadas. Os recursos não são dados, mas construções; a definição da especificidade é o resultado de um trabalho e as rendas procedem de diferenciações bemsucedidas. Todas essas tarefas exigem de atores (privados, associativos, públicos) um acompanhamento que renova as condições de eficiência e de legitimidade do exercício do poder; daí a atenção dada às formas de governança (LACOMBE, 2014, p. 11, tradução nossa).
\end{abstract}

Para que uma dinâmica de desenvolvimento territorial centrada na identificação e ativação de recursos específicos seja deflagrada, o reconhecimento da importância dos efeitos de proximidade, de endogenia das dinâmicas, das lógicas de reciprocidade na valorização dos recursos territoriais e, principalmente, dos regimes territoriais de governança representam um aspecto central (BÉRARD et al., 2005).

O que acontece nos territórios é, portanto, o surgimento de novos modos de governança que desafiam atores e instituições, pois impõem mecanismos inéditos de gestão de conflitos. Esse processo deve pautar-se na criação de uma coordenação eficaz entre atores territoriais que permita a realização de um bom inventário de recursos específicos e dinamize a execução de ações que consolidem o enfoque da CBST. Para tanto, os atores associativos são fundamentais para apoiar e organizar as ações em curso. Vale ressaltar que, muitas vezes, esse tipo de ator faz parte ou está imbricado com o setor privado, mas se distingue desse último pela sua natureza coletiva (CAMPAGNE; PECQUEUR, 2014).

A fim de melhor demonstrar a estrutura geral da CBST e o papel de cada tipo de ator territorial nessa estratégia de desenvolvimento, a Figura 1 apresenta um esboço de como produtos, serviços, ambiente e atores territoriais se relacionam no processo de construção de uma CBST.

Figura 1. Sistema de governança territorial e estrutura de uma CBST 


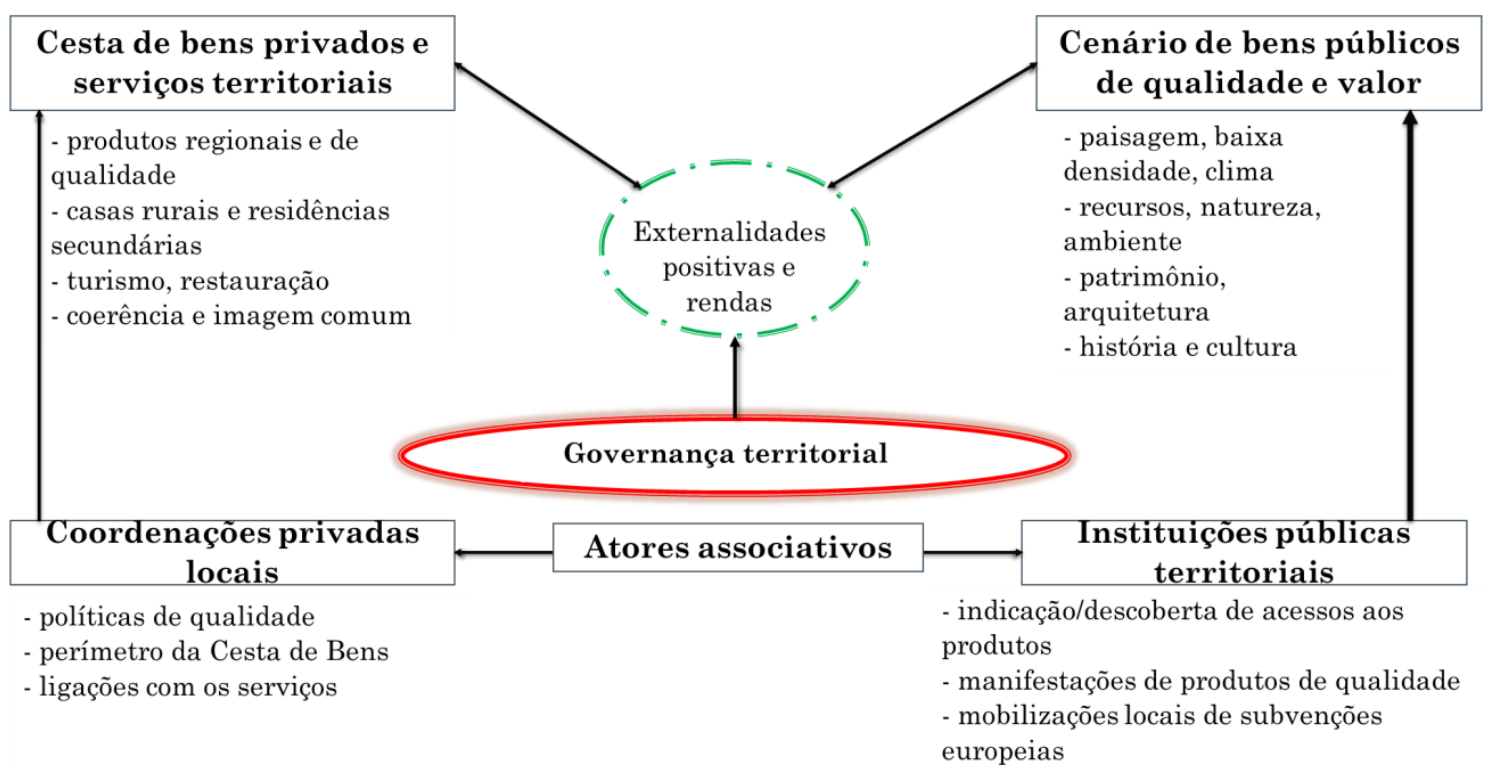

Fonte: Adaptado de Mollard (2005); Campagne; Pecqueur (2014).

Em síntese, uma CBST consiste em uma oferta compósita de produtos e serviços territoriais, que prioriza os circuitos curtos de comercialização, estimulando o reconhecimento da qualidade dos produtos e serviços específicos da parte dos consumidores locais e externos, a exemplo de turistas e outras categorias de apreciadores de produtos típicos. Portanto, envolver os usuários ou consumidores de produtos e serviços da "Cesta" é tão importante quanto construir um sistema de governança territorial compartilhada por atores públicos, privados e associativos. Essas três categorias de atores desempenham funções diferenciadas, mas interativas no processo de construção da CBST. Os atores públicos cumprem o papel de disponibilizar, por meio dos seus serviços descentralizados, o acesso a tudo o que diz respeito a bens e serviços públicos (infraestrutura, equipamentos e serviços). Já os associativos, como cooperativas ou associações de agricultores familiares e de empresários, por exemplo, e privados, tais como produtores de bens diferenciados e proprietários de pousadas e restaurantes desempenham o papel de geração de renda e emprego, promovendo externalidades positivas para o território (CAMPAGNE; PECQUEUR, 2014).

\section{Serra Catarinense: produtos específicos e cenário}

Com base na formulação cunhada por Pecqueur (2005) de território dado e território construído, compreende-se neste estudo como território dado a delimitação administrativa da Agência de Desenvolvimento Regional de São Joaquim, que inclui, além desse município, Urupema, Bom Retiro, Rio Rufino, Urubici e Bom Jardim da Serra (Figura 2). Essa estrutura administrativa fez parte da política de descentralização do governo do estado de Santa Catarina iniciada em 2003 (OGANAUSKAS FILHO, 2016), e que foi, recentemente, desativada pelo atual governo do estado. Trata-se de uma região de baixa densidade populacional, com cerca de 54 mil habitantes, dos quais pouco mais da metade reside em São Joaquim. Desse total, $43 \%$ vivem no meio rural e desenvolvem atividades agropecuárias. 
Para atingir os objetivos deste artigo, a análise se volta, por um lado, para as ações coletivas de diferenciação do queijo artesanal serrano, maçã, vinho de altitude e o mel de melato, produtos relacionados a processos de obtenção de IG e com destacada importância socioeconômica na Serra Catarinense ${ }^{4}$. Por outro lado, merece tratamento diferenciado na discussão a especificidade do turismo rural associado ao cenário do território (paisagem, clima, patrimônio histórico, gastronômico e cultural), demonstrando seu potencial de promover a interligação dos produtos da CBST.

Figura 2. Localização geográfica dos municípios da extinta Agência de Desenvolvimento Regional de São Joaquim

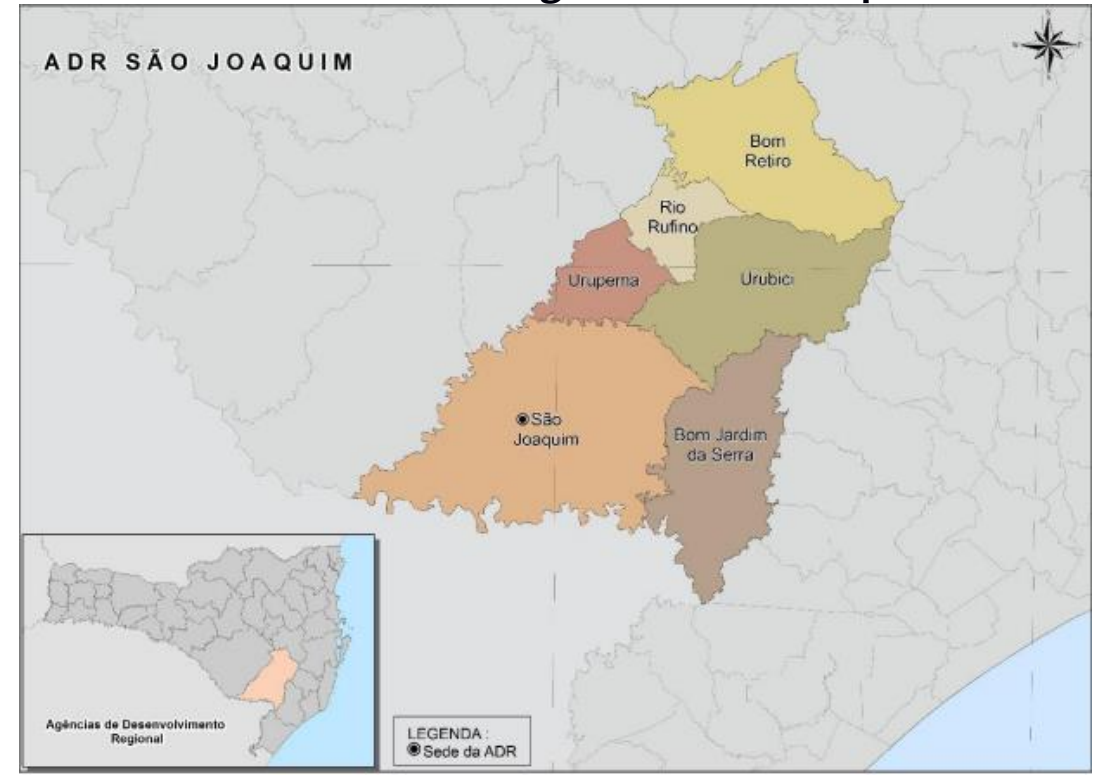

Fonte: Governo do Estado de Santa Catarina (2017).

\subsection{Os principais produtos de qualidade territorial}

A Serra Catarinense, mesmo sendo um território com baixos índices socioeconômicos, quando comparada com outras regiões de Santa Catarina, contém uma importante riqueza de produtos e serviços específicos. Dentre esses, o queijo artesanal serrano figura como produto processado mais antigo do território, com imagem relacionada à sua história e com uma grande demanda e reconhecimento da parte de consumidores, inclusive, de fora do território. Trata-se de um queijo produzido com leite cru integral originário de vacas de corte criadas nos campos nativos da região, processo que remonta ao período do tropeirismo no Século XVIII. Esses elementos conjugados propiciam uma especificidade no sabor e textura do queijo (YAMAGUCHI et al., 2016).

O queijo artesanal serrano é fabricado de forma artesanal com produção de pequenas quantidades por agricultores familiares, curado sobre madeira de araucária

\footnotetext{
${ }^{4}$ Além dos produtos associados à construção de IG, a região tem outros produtos e serviços típicos, com destaque para a goiaba serrana, a carne frescal e o artesanato de vime. No quadro deste artigo se privilegiou a análise dos produtos e serviços de maior notoriedade territorial e impactos socioeconômicos.
} 
por um período mínimo de 30 dias (Figura 3). Tem a sua origem entre os descentes portugueses que fizeram parte da colonização da região. Por aproximadamente dois séculos, esse tipo de queijo era transportado em lombo de muares para ser trocado por outras mercadorias não produzidas na região, como sal, café, açúcar, dentre outros (PIEPER; CRUZ, 2014). Trata-se do primeiro produto da Serra Catarinense mobilizado por atores locais para a obtenção de uma IG. O processo de criação da IG do queijo artesanal serrano ainda está em curso, mas o pedido já foi submetido, no fim do ano de 2017, ao Instituto Nacional da Propriedade Industrial (INPI) e se encontra em processo final de avaliação. O queijo artesanal serrano será o terceiro produto catarinense com esse tipo de selo de qualidade. O primeiro foi obtido por agricultores e proprietários de vinícolas implicados com o cultivo e processamento da uva goethe, no sul do estado, com destaque para o espumante produzido com essa variedade de uva (CERDAN et al., 2018) e o segundo corresponde à banana de Corupá, produzida na região norte do estado de Santa Catarina.

\section{Figura 3. Queijo artesanal serrano o processo de cura sobre madeira de araucária}

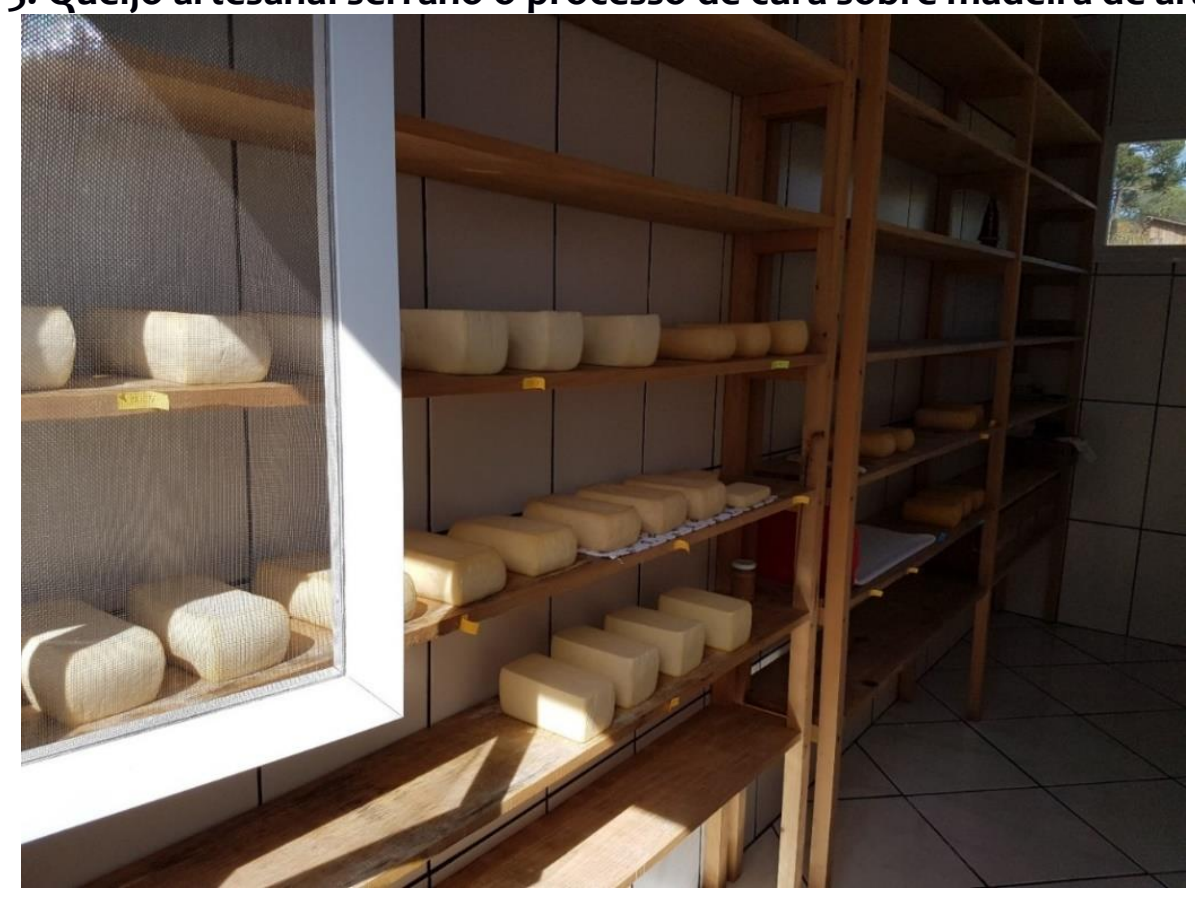

Fonte: Acervo dos autores, 2018.

A iniciativa da IG do queijo artesanal serrano articula produtores de Santa Catarina e do Rio Grande do Sul, graças a uma parceria que envolve profissionais da Empresa de Pesquisa Agropecuária e Extensão Rural de Santa Catarina (EPAGRI), da Empresa de Assistência Técnica e Extensão Rural do Rio Grande do Sul, do Ministério da Agricultura, Pecuária e Abastecimento e da Associação de Municípios da Região Serrana (AMURES) (CÓRDOVA et al., 2015). No estado de Santa Catarina, o processo de criação da IG mobilizou parte dos produtores desse tipo de queijo, os quais formaram a Associação de Produtores de Queijo Artesanal Serrano da Serra Catarinense (APROSERRA). Essa associação agrupa 42 agricultores familiares proprietários de queijarias, das quais sete já se adequaram às normas sanitárias e de qualidade requeridas no processo de produção e comercialização. As demais 
encontram-se em fase de adaptação à legislação, especialmente no que se refere às normas sanitárias.

A necessidade de uma organização formal dos produtores para cumprir com as exigências técnicas e legais da IG fez com que um grupo de produtores estivesse melhor preparado para adotar as orientações técnicas. Os agricultores que já haviam investido na construção de queijarias e seguiram as normas sanitárias exigidas pela legislação lograram vantagens em relação a seus pares que, por razões diversas, não efetuaram esse mesmo procedimento. Entretanto, é sabido que essas organizações precisam de tempo para que dominem a arte da gestão de processos coletivos e assumam os desafios para lograr vantagens decorrentes da obtenção de uma IG. Ou seja, o auxílio de outras organizações profissionais, a exemplo da EPAGRI e do Serviço de Apoio às Micro e Pequenas Empresas de Santa Catarina (SEBRAE-SC) 5 , tem se mostrado fundamental (SANTOS, 2017).

As características ligadas à produção desse tipo de queijo, mencionadas acima, permitem qualificá-lo, à luz do enfoque da CBST, como um ativo territorial específico. Trata-se de um produto comercializado no estado inteiro, com produção e reputação semelhante no estado vizinho do Rio Grande do Sul, que possui um reconhecimento da sua qualidade e especificidade territorial por parte do consumidor. Uma agricultora produtora de queijo de São Joaquim, quando entrevistada, ressaltou a notoriedade e a qualidade do produto comprovada pela alta demanda do consumidor:

Ele é bem diferente dos outros. O gosto, sabor, até a maturação. Aí, essa semana eu despachei tudo [para] os freguês que ia chegando. Gente, eu não tenho queijo! Então, essa semana eu tô dispensando o freguês (Agricultora produtora de queijo serrano, São Joaquim/SC, abr./2018).

Além do sabor específico, esse produto possui vínculos com a origem da formação do território da Serra Catarinense, por se tratar de um queijo que remonta ao período colonial. Além disso, há uma relação de proximidade entre os agricultores produtores, consumidores, varejistas e comerciantes, que fortalece as vantagens associadas à especificidade do queijo artesanal serrano (SANTOS et al., 2016).

Outro produto com grande notoriedade no território é a maçãa, que se destaca pela sua importância econômica na região. O cultivo da macieira está associado aos serviços públicos de pesquisa e extensão rural do governo do estado que, na década de 1970, promoveu o Programa de Fruticultura de Clima Temperado. No campo da pesquisa, a instalação de uma estação experimental da atual EPAGRI contou com uma sólida parceria técnica com a Agência de Cooperação Internacional do Japão (JICA) (CORDEIRO, 2006).

Atualmente, o município de São Joaquim concentra a maioria dos produtores de maçã do estado devido às condições climáticas mais favoráveis à produção. As cultivares gala e fuji, produzidas na Serra Catarinense, são reconhecidas pelo maior tamanho, melhor sabor, crocância e coloração (Figura 4), quando comparadas aos frutos originários de outras zonas de produção do país, que possuem menor altitude

5 O SEBRAE-SC está executando o projeto "Serra de Sabores" na região, previsto para o período de 2017 a 2019, cujas metas preveem a constituição das IG da maçã, vinhos de altitude e mel de melato. 
e qualidade do frio ${ }^{6}$, notadamente Fraiburgo (SC) e Vacaria (RS). O microclima existente na região e seu cultivo em unidades agrícolas familiares explicam, em grande parte, essa qualidade superior.

\section{Figura 4. Maçã da região de São Joaquim}

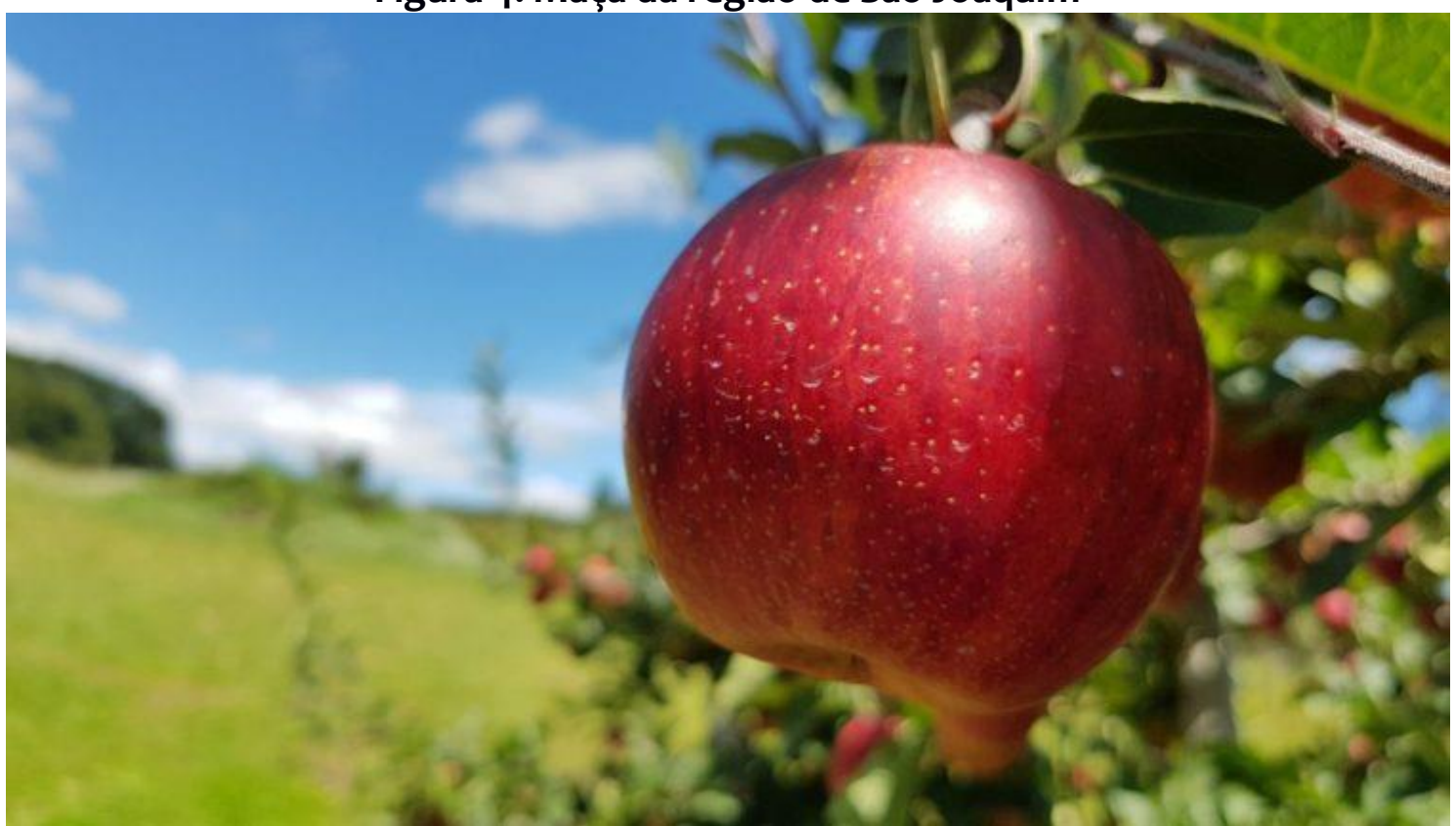

Fonte: São Joaquim Online, 2018.

Embora a produção de maçã ainda seja o principal produto econômico da Serra Catarinense, para muitos entrevistados, é perceptível que está em curso um processo de estagnação decorrente de variações climáticas que influenciam a sua produtividade e qualidade. Além disso, trata-se de um produto cujo preço sofre quedas frequentes em decorrência da importação de maçãs, sobretudo, da Argentina. Outro fator ressaltado nas entrevistas é a marcada presença de grandes empresas que se instalaram no município de São Joaquim, as quais têm hegemonia comercial e atuam em outras zonas produtoras. Estima-se que essas empresas comercializam $70 \%$ da maçã produzida na região, fazendo com que a qualidade superior dos frutos não seja valorizada nos mercados, uma vez que a produção local é misturada com frutos de qualidade inferior produzidos em outras regiões (CAZELLA et al., 2008).

Essa situação está correlacionada ao fato da grande maioria dos produtores de maçã ser de porte pequeno e médio. A maioria desses produtores firma contratos de safra com essas empresas, que impõem o valor do quilo da maçã e a data de pagamento (BITTENCOURT et al., 2011). Uma parcela minoritária de produtores é sócia de uma das cinco cooperativas existentes na região: Cooperativa Agrícola de São Joaquim (Sanjo), Cooperativa Regional Serrana (Cooperserra), Cooperativa Agrícola Frutas de Ouro (Frutas de Ouro), Cooperativa Agropecuária de Urupema (Coopema) e Cooperativa Ecológica de São Joaquim e Região (Econeve). As quatro

${ }^{6}$ O clima da região da Serra Catarinense interfere diretamente na qualidade da maçã devido ao gradiente térmico. A diferença de temperatura entre o dia e a noite varia de 10 a $14^{\circ} \mathrm{C}$, condição considerada ideal, pois permite que os produtos metabolizados pela planta durante o dia sejam armazenados no fruto à noite. 
primeiras, por terem uma estrutura de armazenamento das frutas, conseguem um melhor preço na venda dos seus frutos. Já os produtores de maçã orgânica, sem o uso de adubos e agrotóxicos sintéticos, associados à Econeve, se inserem em um mercado de alta demanda, sendo capaz de negociar sua produção por um maior preço quando comparado ao obtido pelo comércio de maçãs em cultivo convencional.

Diante desse quadro, uma estratégia de proteção e valorização da maçã da Serra Catarinense, por meio da implantação de uma IG, encontra-se em fase embrionária de estruturação. Essa iniciativa é coordenada pelo SEBRAE, em parceria com a EPAGRI e as quatro primeiras cooperativas acima mencionadas. A tentativa de agregar valor à maçã por meio de uma IG não é um caso isolado promovido pelo SEBRAE. Desde 2012, essa organização promove ações no estado sobre esse tema, tendo identificado 27 produtos catarinenses com potencial para obtenção de uma IG (SAKR; DALLABRIDA, 2015).

O processo de IG da maçã serrana ainda está em discussão, principalmente no que se refere à delimitação da área de abrangência e às variedades a serem reconhecidas como portadoras de especificidades. Os principais fatores que promovem qualidades diferenciadas aos frutos estão associados à quantidade de horas de frio e à altitude, conferindo um sabor específico à maçã serrana. A delimitação da área de abrangência da IG recai sobre uma decisão embasada por dados meteorológicos, mas ainda sem uma definição de parâmetros consensuais entre os atores envolvidos - pesquisadores, empresários e agricultores - para a definição desse perímetro. Em relação às variedades, em que pese o interesse desses atores em incluir os frutos da variedade gala, tem-se um consenso de que a variedade fuji se diferencia nas análises organolépticas, principalmente pela quantidade de açúcar e uma leve acidez. Esse processo representa um tema a ser aprofundado por novos estudos, pois revela um aprendizado coletivo sobre a complexidade de fatores em jogo no momento de delimitar abrangência e volume de produção de produtos de qualidade a serem diferenciados por uma IG.

À luz do enfoque teórico-metodológico da CBST, é possível afirmar que a maçã fuji da Serra Catarinense figura, até o momento, como um ativo territorial genérico, já que seu processo de comercialização ocorre em mercados que não valorizam suas qualidades específicas. O processo de construção da IG dessa variedade de maçã pode mudar essa condição, atribuindo um caráter de ativo específico, pelo menos para uma parcela da produção. Entretanto, para passar da condição de ativo genérico para ativo específico, um longo caminho ainda precisa ser trilhado, pois não se trata, somente, de colocar um selo de qualidade no produto, mas de que o produto e seu respectivo selo sejam reconhecidos pelos consumidores.

Assim como a maçã, a produção do vinho de altitude, apesar de possuir uma trajetória histórica recente no território, é beneficiada pelas características edafoclimáticas da Serra Catarinense. O diferencial de qualidade desse produto, chama a atenção de diferentes apreciadores de vinhos do mundo. A história vitivinícola na região iniciou-se, na década de 1990, a partir de um projeto de pesquisa da EPAGRI, que identificou o clima e a altitude do município de São Joaquim como propícios ao amadurecimento mais tardio das uvas. Essa particularidade proporciona frutos mais escuros, o que permite uma maior qualidade no processo de vinificação (Figura 5). Em um curto prazo, São Joaquim passou do anonimato no mapa 
vitivinícola brasileiro para o município com a maior área plantada com uvas viníferas do estado (CORDEIRO, 2006).

Figura 5. Produção de uvas viníferas, em fim de ciclo, no município de São Joaquim

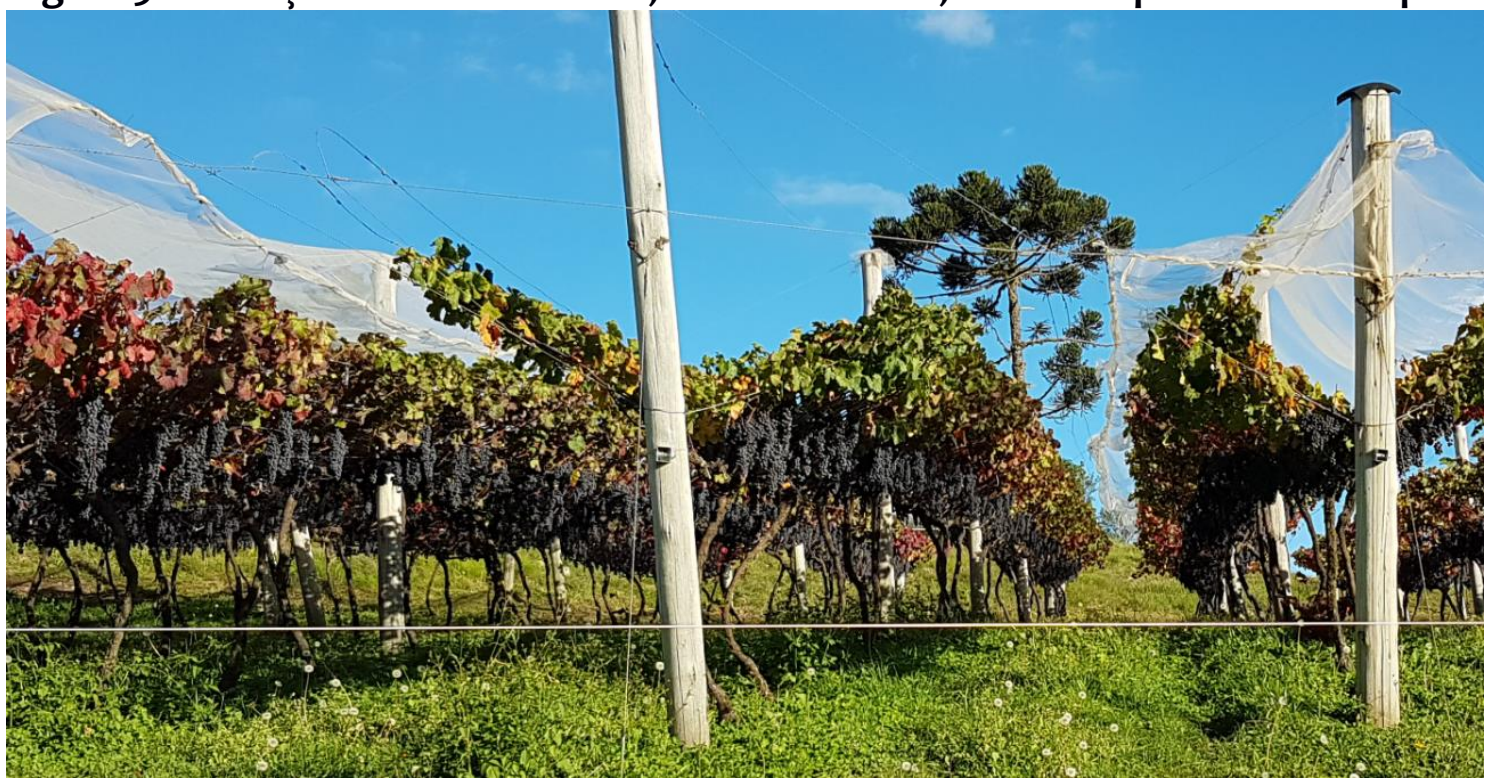

Fonte: Acervo dos autores, 2018.

A continuidade das pesquisas da EPAGRI, em parceria com produtores proprietários de vinícolas, Empresa Brasileira de Pesquisa e Agropecuária (Embrapa) e Universidade Federal de Santa Catarina, fez com que a adaptação das cultivares de videira na região da Serra Catarinense propiciasse a produção de vinhos de alta qualidade. Segundo Brighenti et al. (2013), as cultivares que possuem um ciclo intermediário, em áreas com altitude superior ou igual a 1.300 metros, apresentam frutos com características ideais à produção de vinhos de alta qualidade.

Como se trata de um produto novo e de alto custo de investimento, a maioria das vinícolas da Serra Catarinense pertence a empreendedores de outras regiões, que vislumbraram nos vinhos de altitude uma grande oportunidade de negócios. Diferentemente da maçã, não se teve, até o momento, a difusão desse tipo de cultivo para um público mais amplo, em especial entre agricultores familiares. Tais empreendedores formaram a Associação Vinho de Altitude a qual é composta por 21 associados dos municípios de São Joaquim, Campos Novos, Água Doce, Treze Tilhas, Bocaina do Sul e Caçador. Juntos, esses associados cultivam cerca de 279 ha de uvas viníferas. Ainda que essa Associação não reúna somente produtores e proprietários de cantinas da região de estudo, a organização desses proprietários de vinhedos e respectivas vinícolas tem sido relevante no processo de diferenciação mercadológica dos vinhos de altitude.

Essas empresas vinícolas têm como estratégia competitiva a elevada qualidade de seus produtos, dedicando-se à elaboração de vinhos de alto padrão, que realcem as características do território, especialmente aquelas derivadas da elevada altitude. Dentre as ações em curso capitaneadas pela Associação Vinho de Altitude destaca-se o processo de estruturação da IG dos vinhos de altitude e a implantação do Projeto de Enoturismo, ambos com o apoio do SEBRAE. Essa modalidade de turismo representa uma importante estratégia comercial das vinícolas instaladas na 
região. Para Losso e Pereira (2012), trata-se de uma atividade altamente promissora por agregar valor ao produto e propiciar ao turista a experiência de degustar vinhos de qualidade em meio as belezas cênicas do vinhedo e da Serra Catarinense como um todo.

Mesmo sendo um produto recente, o vinho de altitude pode ser qualificado como um ativo territorial específico da Serra Catarinense, pelas suas características organolépticas singulares e pelo sistema organizacional que lhe envolve. Além de contar com uma forte articulação da parte dos atores privados do território, a produção de vinho respalda-se também no apoio de atores públicos, em especial da EPAGRI e da Embrapa.

Outro produto serrano portador de características específicas ligadas ao território é o mel de melato. Esse tipo de mel é produzido a partir de secreções de partes vivas de árvores de bracatinga (Mimosa scabrella), planta nativa de zonas frias do sul do país, que têm sua seiva sugada pelo inseto chamado cochonilha. Esse inseto digere a seiva, eliminando gotas de melato (SALOMÉ, 2002). Esse processo ocorre no inverno quando as floradas naturais de outras espécies são inexistentes. Assim, as abelhas têm nessas gotas de melato um importante alimento para esse período de escassez de outras fontes de alimentos. Todo esse processo propicia um mel de qualidade diferenciada, que apresenta um menor teor de glicose, não cristaliza e cuja coloração escura se assemelha ao melado de cana-de-açúcar (Figura 6). A sua produção ocorre em biênios associados à ocorrência do ciclo da cochonilha (BONILHA, 2012).

Figura 5. (A) Abelha se alimentando das gotas de melato geradas pelas cochonilhas. (B) Mel de melato extraído das colmeias sendo envazado

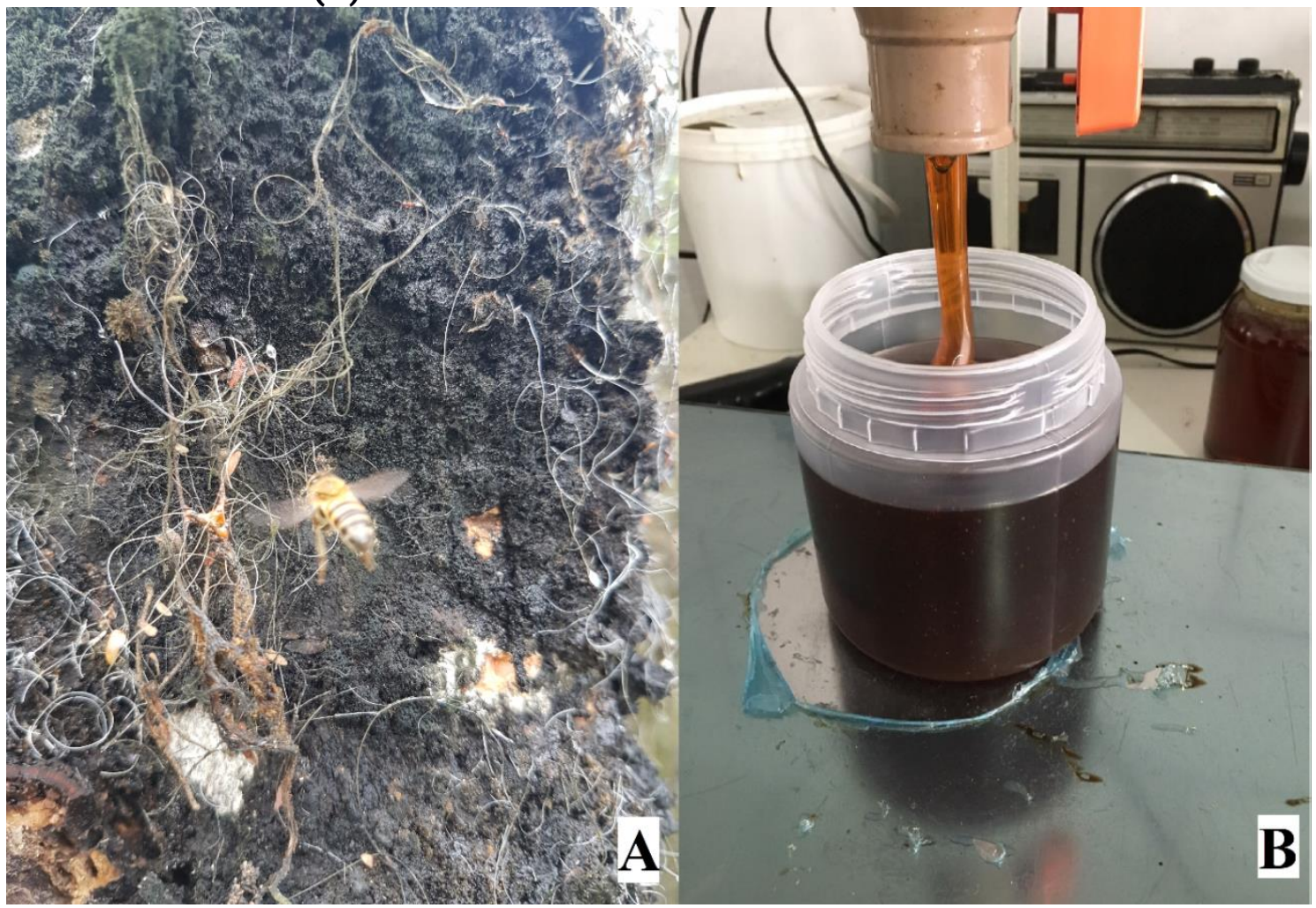

Fonte: Acervo dos autores, 2018. 
Até recentemente, a coloração mais escura e o gosto um pouco amargo, em comparação ao mel floral, fazia com que esse produto fosse desvalorizado tanto pelos produtores, quanto pelos consumidores locais. Entretanto, as características específicas do produto chamaram a atenção de exportadores alemães, que passaram a comprar a produção local. Hoje, a maior parte do mel de melato de bracatinga é exportado para a Alemanha. Alguns produtores entrevistados afirmam que $95 \%$ do que é produzido é vendido para o exterior.

Esse grande volume de exportação é justificado pela qualidade diferenciada do mel de melato em comparação aos demais méis florais. De acordo com Azevedo (2017), o mel de melato de bracatinga se diferencia dos demais méis florais devido à alta concentração e diversidade de compostos fenólicos, presença marcante de macronutrientes, como potássio, cálcio e magnésio, além de um menor teor de glicose. Desse modo, pode-se afirmar que o mel de melato possui propriedades funcionais que o diferenciam dos demais tipos de méis.

Além da valorização promovida pelo mercado externo, esse tipo de mel pode ganhar um novo impulso com a certificação orgânica7 e a criação de uma IG. Alguns comerciantes que intermediam a exportação preferem produtos com esse tipo de certificação, pois na Europa as IG têm um grande reconhecimento da parte dos consumidores. Nesse caso, isso pode refletir no maior valor final do mel comercializado. Porém, a frágil organização dos apicultores serranos, estimados em cerca de 290 produtores pela Federação das Associações de Apicultores e Meliponicultores de Santa Catarina (FAASC, 2016), explica o fato da maior parte do produto comercializado ser intermediada por entrepostos de outras regiões do estado, sem nenhuma referência ao território de origem. Atualmente, no território serrano existem apenas duas organizações em torno do mel de melato: a Associação Serrana de Apicultores (ASA) e a Associação de Apicultores de Bom Retiro (APIBOM) localizadas, respectivamente, em São Joaquim e Bom Jardim da Serra.

A passagem abaixo exemplifica nas palavras de um entrevistado como esse produto territorial específico pode perder sua notoriedade em decorrência da precária organização dos atores sociais implicados com o mel de melato. A prática de alguns entrepostos de fazerem a mistura desse mel com outros méis com o propósito de aumentar a quantidade exportada como sendo mel de melato de bracatinga, resulta não só na queda de qualidade do produto final, mas na quebra de confiança dos compradores estrangeiros. Essa mistura de méis são denominados pelos apicultores da região de "bugio" por apresentar uma coloração mais clara e uma textura mais fina, o que difere de um mel de melato puro.

O problema é que tu vendes o mel para entreposto e eles fazem a mistura lá.... Aí quando chega lá na Alemanha ou Estados Unidos, mais a Alemanha.... Enquanto aqui no Brasil fazem teste, tem três, quatro problemas no mel. Na Alemanha, eles descobrem mil problemas no mel.... Sai daqui um mel bom, de qualidade, chega lá eles compram mel do Piauí [estado da região nordeste do país], compraram, colocaram junto. Aí homogeneíza tudo, quando chega lá tem muito umidade. Aí vem muito

\footnotetext{
7 Trata-se de um procedimento que assegura que o produto com o selo orgânico obedece toda a regulamentação vigente na lei 10.831/2003, a qual define os parâmetros de exigência para produtos de origem animal e vegetal sem a utilização de insumos sintéticos.
} 
umidade. Porque o mel de lá tem muito umidade, né! (Apicultor, Bom Retiro/SC, jun.2018).

A iniciativa de construção de uma IG para esse produto típico de regiões de altitude do Sul do País, coordenada pelo SEBRAE, ainda se encontra em fase inicial. A fragilidade da organização dos apicultores da região certamente representa um desafio suplementar. A iniciativa representa, no entanto, uma forma de criar especificidade e valorizar o mel de melato da Serra Catarinense, em relação às produções existentes em outras zonas com características climáticas semelhantes. Aqui, tem-se um produto típico produzido em uma zona que extrapola os limites da região de estudo. A especificação desse tipo de mel pode ser apropriada por outra zona produtora, pois está intimamente associada à ação coletiva, sobretudo, dos apicultores implicados com o processo.

Apesar da desarticulação dos apicultores serranos, pode-se classificar o mel de melato de bracatinga como um recurso territorial específico em processo de ser transformado em ativo específico. Embora se tenha vários aspectos que fazem dele um produto específico, esse tipo de mel ainda é pouco valorizado no território, mas muito apreciado pelo mercado externo. A ausência de articulação entre os produtores e o incipiente reconhecimento dos atributos territoriais do produto pelos consumidores no território apontam para a necessidade de um maior tempo e esforço organizacional dos distintos atores sociais envolvidos no sentido de inserir o mel de melato entre os produtos com potencial de compor a CBST da Serra Catarinense.

\subsection{Um cenário favorável ao turismo rural}

A Serra Catarinense apresenta uma paisagem característica, rica pela sua vegetação nativa, com destaque para a araucária intercalada com as áreas de campos nativos (Figura 7). A região possui um clima fortemente marcado pelos longos períodos de frio, que perduram por quatro a seis meses. O inverno rigoroso e o verão ameno, respectivamente, com temperaturas abaixo de zero e de $22^{\circ} \mathrm{C}$, contribuem para definir a forma de viver, bem como as características de alguns produtos e serviços existentes na região. 
Figura 7. Paisagem da Serra Catarinense

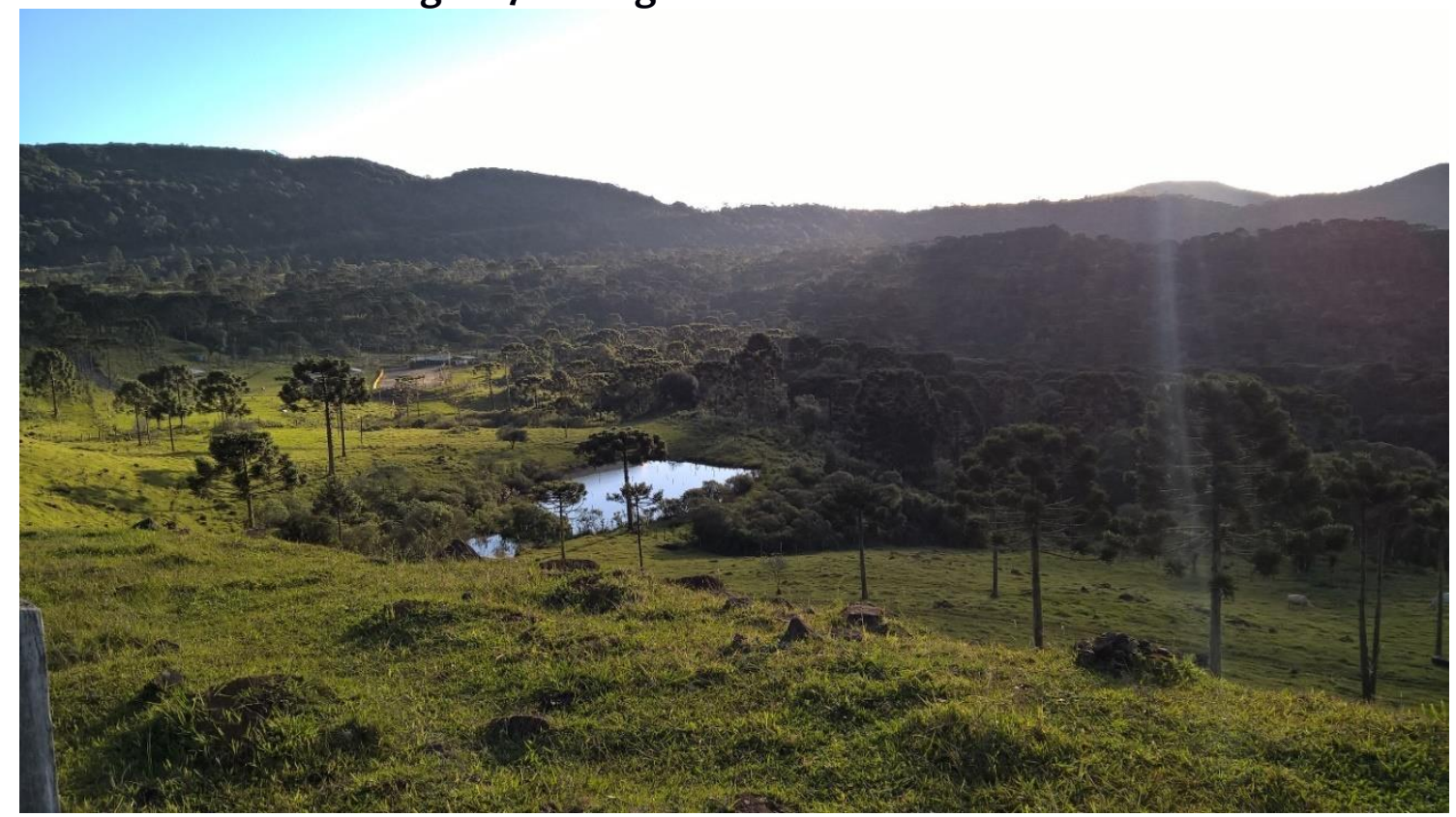

Fonte: Acervo dos autores, 2018.

O frio intenso no inverno propicia a formação de geadas e, ocasionalmente, de neve, fenômeno que explica a notoriedade da região, que desfruta da publicidade gratuita feita pelas mídias nacionais devido ao seu clima. Durante a estação de inverno, a Serra Catarinense muda sua rotina pacata e recebe um grande número de turistas de diversas regiões do Brasil. A formação de grandes cânions e serras amplia as belezas naturais compostas por vastas florestas, uma grande diversidade de pássaros, cachoeiras, inscrições rupestres, entre outros atrativos, que permitem aos turistas realizarem uma série de atividades de ecoturismo, agroturismo e turismo de aventura. Mais recentemente, o enoturismo apresenta-se como um novo atrativo, principalmente no município de São Joaquim, abrangendo visitas às vinícolas, além de piqueniques e degustações no interior dos parreirais sob o pôr do sol (SILVA; SOMMER, 2005). A Vindima, festa da colheita da uva, atrai um fluxo significativo de turistas entre os meses de maio e abril.

Esses atributos territoriais associados ao clima, paisagem e meio ambiente representam "componentes" de uma potencial CBST. Os atrativos históricos, culturais e naturais do território colocam à disposição dos turistas um leque de opções a ser desfrutado. Nas últimas décadas, o setor de turismo tem ampliado as opções de hospedagem, inclusive do ramo do turismo rural. Algumas famílias de agricultores familiares têm aderido às atividades de acolhimento de turistas como uma alternativa de diversificação de renda. Uma parcela dessas famílias aproveita a estrutura de antigas fazendas de gado e as utilizam como hotéis fazenda. Outras investem em infraestrutura nova e direcionam suas atividades de forma a priorizar 0 acolhimento de turistas em unidades agrícolas familiares (CORDEIRO, 2006).

Essas unidades agrícolas familiares que empreendem no setor turístico se diferenciam de outros estabelecimentos, pois a prestação de serviços se associa à produção agropecuária. Além disso, a cultura e a tradição serrana representam um atrativo adicional para os turistas. 
[...] A gente tem turismo rural de raiz, de ter a vivência, de você andar a cavalo, fazer uma trilha, de você fazer um passeio de trator, de você usufruir da infraestrutura de pontes em cima de rios, para você tornar essa experiência ou proporcionar essa experiência para as pessoas que não tiveram isso. Fazer uma sapecada de pinhão, então, uma colheita, experimentar uma fruta no pé, tudo isso é diferente daquele que tem um empreendimento lá que tem uma estrutura linda e bonita, mas é só estrutura. Então, essa vivência do campo, de você se melecar mesmo. Dizendo assim, de tudo que o meio envolve, acho que é que dá o diferencial (Dono de pousada, Urubici/SC, abr/2018).

Esse propósito de propiciar aos turistas uma conexão com a natureza e com práticas tradicionais corrobora os resultados de um estudo de caso elaborado por Bathke (2002, p.86), no município de São Joaquim. De acordo com esse autor, os turistas procuram a região pelas seguintes características:

[...] paz que o campo oferece; da paisagem que cerca a região campos cercados de taipas, montanhas, florestas com araucária, rios com trutas; e das virtudes simples encontradas na vida campeira: a ordenha do gado, as lidas dos peões, os passeios a cavalo, as histórias ouvidas em volta ao fogo de chão ou na frente da lareira, degustando a farta e típica gastronomia da região.

O turismo rural da Serra Catarinense tem registrado taxas de crescimento exponencial, com forte apelo às especificidades do território, como o clima, a paisagem, a cultura e o meio ambiente, além de ações que valorizam os produtos agrícolas e a culinária típica da região. Alguns pratos se destacam nas refeições servidas nas pousadas e restaurantes, a exemplo da paçoca de pinhão e do entrevero ${ }^{8}$. A crescente demanda do turismo propiciou a valorização da diversidade gastronômica, do artesanato, da cultura da região e, por conseguinte, do saber-fazer de cada produto, com destaque para a figura da mulher, principal responsável pela transformação artesanal desses produtos (TORESAN et al., 2002).

Outro ponto interessante que o turismo rural tem modificado na dinâmica dos agricultores familiares da Serra Catarinense é a diversificação da comercialização dos seus produtos. Parte da produção artesanal é comercializada diretamente aos turistas, às pousadas e demais empreendedores que oferecem algum tipo de serviço para os turistas. Algumas famílias processam frutos in natura em forma de geleias, sucos, polpas, doces e bolos, para fornecer às pousadas ou até mesmo comercializar na forma de café colonial9 ${ }^{9}$ nas suas propriedades.

Dentro desses novos meios de inserção ao mercado, alguns produtores de maçã têm adotado uma estratégia inovadora de comercialização direta, denominada de colhe e pague. Nas épocas de produção do fruto, o agricultor familiar separa uma área da sua produção, a qual o turista visita e paga um valor fixo para colher a fruta diretamente da árvore, além de degustá-la no próprio pomar. Por se tratar de uma

\footnotetext{
${ }^{8} \mathrm{O}$ entrevero é um prato típico da Serra Catarinense feito a base de pinhão misturado com legumes e diferentes tipos de carnes (bovina, suína e aves), com destaque para a carne frescal.

9 Trata-se da oferta de uma variedade de receitas artesanais, comumente associados à tradição alimentar de agricultores de origem europeia que colonizaram a região sul do país servidos, servidos para turistas e moradores locais
} 
fruta amplamente consumida no Brasil, mas com uma produção restrita a regiões mais frias do país, a escolha da fruta diretamente da árvore se torna um momento único para essas pessoas.

Assim, o turismo rural da Serra Catarinense pode ser considerado um ativo territorial específico pela abordagem da CBST, já que os atrativos naturais do território explicam, em grande parte, o afluxo expressivo de clientes. Um aspecto associado a essa especificidade é o baixo número de hotéis e a existência de diversas pousadas rurais, que lotam em toda temporada de inverno e mantêm uma razoável taxa de ocupação durante o verão. A importância econômica desse serviço no território da Serra Catarinense tem crescido de forma contínua nos últimos anos, posto que todos os seis municípios têm secretarias de turismo ativas e dois deles organizaram conselhos municipais de turismo. Esses municípios também possuem secretarias de agricultura, mas nos processos de qualificação dos produtos as secretarias de turismo figuram como novos espaços de apoio as essas iniciativas.

Todos os municípios dispõem em seus portais na internet publicidades de seus atrativos turísticos. Além disso, a relevância dessa atividade fica evidente pela presença de organizações associativas em torno desse serviço, a exemplo da Associação de Agroturismo Acolhida na Colônia ${ }^{10}$, Associação Bom Jardinense de Turismo Rural (ABTER), Associação Bom Jardinense de Turismo (ABT), Associação do Trade Turístico de Urubici (POUSERRA) e um grupo informal de guias turísticos. Todos esses atores associativos participam do Conselho de Turismo da Serra Catarinense (CONSERRA), que representa uma inovação e pioneirismo inexistente na maioria dos territórios rurais catarinenses construídos pela ação dos atores sociais. $O$ CONSERRA cumpre o papel de articular as diferentes iniciativas de turismo existentes no território, além de promover o comércio de produtos territoriais típicos e de qualidade e a consequente geração de renda. Por fim, tais organizações possuem uma trajetória recente no território, com destaque para o pioneirismo da Acolhida na Colônia. O sucesso relativo dessa associação estimulou indiretamente a criação de várias pousadas rurais geridas tanto por atores locais, quanto por empreendedores externos ao território.

O turismo rural, portanto, exerce uma ação de elo entre os diferentes serviços e produtos específicos do território, o que reforça o potencial para a formação de uma CBST. Ao chegar na Serra Catarinense, o turista descobre vários outros produtos do território, já que os serviços de hospedagens valorizam, ainda que de forma incipiente, os produtos típicos, como o queijo artesanal serrano, a maçã, o vinho de altitude, o mel de melato, os pratos da culinária local e, sobretudo, as belezas cênicas do território ${ }^{11}$.

Por fim, na Serra Catarinense há subsistemas de governança correlacionados aos atores implicados com ações de diferenciação da qualidade de produtos e serviços. No entanto, a presença de distintas categorias de atores atuando de diferentes formas com cada um dos produtos e serviços analisados, com destaque

\footnotetext{
10 Associação criada em 1999 no Brasil, composta atualmente por 180 famílias de agricultores orgânicos, que promovem o agroturismo ecológico. Esta iniciativa tem parceria com a organização Accueil Paysan da França, criada em 1987.

${ }^{11}$ A pesquisa de campo realizada para este estudo não contemplou entrevistas com turistas nem com consumidores urbanos dos municípios do território. Trata-se de um tema relevante a ser analisado por novas pesquisas.
} 
para os atores associativos, não implica na existência de uma organização capaz de coordenar o conjunto dessas iniciativas. Em contrapartida existe a perspectiva que, por meio dos processos de IG em curso, ocorra uma articulação dos atores associados aos distintos produtos e serviços. Atualmente, o subsistema de governança do turismo rural é o único que promove a valorização, ainda que de forma incipiente, dos produtos específicos da Serra Catarinense. A Figura 8, a seguir, sintetiza o sistema de governança territorial em processo de construção e os principais produtos e serviços da CBST da Serra Catarinense.

Figura 8. Governança territorial e estrutura da CBST da Serra Catarinense

\begin{tabular}{|c|c|c|}
\hline $\begin{array}{l}\text { Cesta de bens privados e } \\
\text { serviços territoriais }\end{array}$ & & $\begin{array}{l}\text { Cenário de bens públicos de } \\
\text { qualidade e valor }\end{array}$ \\
\hline $\begin{array}{l}\text { - produtos serranos de } \\
\text { qualidade: queijo artesanal } \\
\text { serrano, maçã fuji, vinho de } \\
\text { altitude e mel de melato } \\
\text { - turismo rural, agroturismo } \\
\text { - casas rurais e residências } \\
\text { secundárias } \\
\text { - coerência e imagem comum }\end{array}$ & $\left(\begin{array}{c}\text { Externalidades } \\
\text { positivas e rendas }\end{array}\right.$ & $\begin{array}{l}\text { - campos nativos, matas de } \\
\text { araucária, baixa densidade } \\
\text { populacional, clima frio } \\
\text { (geada e neve) } \\
\text { - recursos, natureza, } \\
\text { ambiente preservado } \\
\text { - patrimônio histórico, } \\
\text { cultural e arquitetura da } \\
\text { colonização tropeira }\end{array}$ \\
\hline \multicolumn{3}{|c|}{ Governança territorial } \\
\hline Coordenações privadas locais & Atores Associativos & Instituições públicas territoriais \\
\hline $\begin{array}{l}\text { - políticas de qualidade iniciadas } \\
\text { pelo processo das IG } \\
\text { - perímetro da extinta ADR de São } \\
\text { Joaquim } \\
\text { - ligações incipientes do turismo } \\
\text { rural com o queijo artesanal } \\
\text { serrano, maçã fuji, vinho de altitude } \\
\text { e mel de melato }\end{array}$ & $\begin{array}{l}\text { - queijo artesanal serrano: } \\
\text { APROSERRA } \\
\text { - maçã fuji: Sanjo, Cooperserra, } \\
\text { Frutas de Ouro, Coopema e } \\
\text { Econeve } \\
\text { - vinho de altitude : Associação } \\
\text { Vinhos de Altitude } \\
\text { - mel de melato: FAASC, ASA e } \\
\text { APIBOM } \\
\text { - turismo rural: Acolhida na } \\
\text { Colônia, POUSERRA, ABT, } \\
\text { ABTER e CONSERRA }\end{array}$ & $\begin{array}{l}\text { - promoção da IG do queijo } \\
\text { artesanal serrano, maçã fuji, vinho } \\
\text { de altitude e mel de melato } \\
\text { - subvenção do SEBRAE para } \\
\text { valorização dos produtos } \\
\text { específicos através da IG } \\
\text { - articulação embrionária entre } \\
\text { SEBRAE, EPAGRI, AMURES e } \\
\text { UFSC }\end{array}$ \\
\hline
\end{tabular}

Fonte: Adaptado pelos autores a partir de Mollard (2005) e Campagne; Pecqueur (2014).

\section{Considerações finais}

Este artigo analisou cinco ativos portadores de especificidades territoriais da Serra Catarinense, sendo eles o queijo artesanal serrano, a maçã, o vinho de altitude, o mel de melato e o turismo rural. Todos esses ativos apresentam uma forte interação com o território, seja de natureza histórica, cultural e biológica, o que diferencia a Serra Catarinense de outras regiões do estado de Santa Catarina. Assim, esses ativos territoriais atrelados ao cenário natural representam uma alternativa para que os atores sociais adotem uma estratégia de desenvolvimento territorial, tendo por base o enfoque da CBST.

A valorização de atributos territoriais, por meio da especificação de seus produtos e serviços, vai além da geração de renda, ainda que esta seja fundamental para os atores sociais envolvidos. Esse tipo de valorização permite a ressignificação de alguns produtos e atores que, até então, permaneciam à margem das dinâmicas territoriais hegemônicas. Na Serra Catarinense, o queijo artesanal serrano, até pouco 
tempo, não representava para os agricultores familiares uma fonte significativa de renda. Atualmente, esse produto possui um papel central na economia de uma parcela importante de unidades produtivas geridas por agricultores familiares. Alguns desses agricultores se dizem queijeiros e não mais pecuaristas, e estabelecimentos gastronômicos fazem questão de especificar o uso desse tipo de queijo em seus pratos. Ou seja, a valorização de produtos específicos fortalece também a cultura alimentar do território e parte do tecido sociocultural implicado com esses recursos territoriais.

Os quatro diferentes projetos de IG analisados neste artigo representam uma forma de aumentar a densidade institucional em torno de produtos com qualidade territorial. As especificações desses produtos por meio dos processos de IG promovem o efeito "cesta". Ou seja, a atração inicial por um produto ou serviço possibilita a descoberta de outros recursos e ativos territoriais específicos. Ademais, o cenário possibilita o aumento desse efeito que culmina numa renda de qualidade territorial. Assim, a Serra Catarinense apresenta as condições propícias para a promoção de iniciativas que conduzam à constituição e, principalmente, o reconhecimento por parte dos consumidores de uma CBST.

Diante do exposto, percebe-se que o território da Serra Catarinense possui quase todos os elementos (cenário, governança territorial e produtos e serviços de qualidade) para deflagrar um processo de desenvolvimento territorial a partir da valorização de recursos e ativos territoriais específicos. Entretanto, persiste uma acentuada desarticulação entre os atores territoriais envolvidos com cada uma das iniciativas para que esses ativos territoriais específicos sejam correlacionados ou interligados, valorizando-os de forma mútua. Até o momento, os atores responsáveis pelos ativos territoriais se apresentam relativamente desarticulados no território, buscando a valorização exclusiva do seu produto. De forma incipiente, o turismo rural tem promovido a ligação entre os ativos territoriais, se apresentando como uma atividade com potencial de propiciar o elo entre os diferentes recursos e ativos territoriais. Além disso, pode-se dizer que a beleza cênica associada à paisagem natural, clima e elementos culturais serranos são os grandes atrativos da Serra Catarinense, que conformam a base dos recursos territoriais, a partir dos quais é possível ativar outros recursos locais existentes. Novos estudos precisam, no entanto, ser realizados para melhor compreender as percepções de turistas e de consumidores locais sobre essas iniciativas. Além disso, um programa de formação dos distintos atores implicados figura como uma ação chave para que os ingredientes da "cesta" não se mantenham dispersos ou desagregados.

\section{REFERÊNCIAS}

AZEVEDO, M. S. Mel de melato de bracatinga (Mimosa scabrella Bentham) do planalto serrano de Santa Catarina: discriminação e potencialidade funcional. 2017.Tese, Programa de Pós-Graduação em Ciência dos Alimentos, Universidade Federal de Santa Catarina, Florianópolis 
BATHKE, M. E. M.O turismo sustentável rural como alternativa complementar de renda à propriedade agrícola: estudo de caso-Fazenda Água Santa-São Joaquim-SC. 2002. Dissertação Programa de Pós-Graduação em Engenharia de Produção, Universidade Federal de Santa Catarina, Florianópolis.Disponível em: <https://repositorio.ufsc.br/bitstream/handle/123456789/82503/196376.pdf?sequenc e=1>. Acesso em: 08 de setembro de 2018 .

BENKO, G.; PECQUEUR, B. Les ressources de territoires et les territoires de ressources. Finisterra, v. 36, n. 71, 2001.

BITTENCOURT, C. C; MATTEI, L. F.; DE SANT'ANNA, P. R.; LONGO C.O.; BARONE, F. $M$ et al. A cadeia produtiva da maçã em Santa Catarina: competitividade segundo produção e packing house. Revista de Administração pública, v. 45, n. 4, p. 11991222, 2011.

BONILHA, E. B. P. Caracterização de cadeia produtiva do mel catarinense: os casos das associações de apicultores de Bom Retiro e da Encosta da Serra.

2012.Dissertação Programa de Pós-Graduação em Agroecossistemas, Universidade Federal de Santa Catarina, Florianópolis

BRIGHENTI, A.F.; BRIGHENTI, E.; BONIN, V.; RUFATO, L. Caracterização fenológica e exigência térmica de diferentes variedades de uvas viníferas em São Joaquim, Santa Catarina - Brasil. Ciência Rural, v.43, p.1162-1167, 2013.

CAZELLA, A. A.; GONCALVES, D. A.; CERDAN, C. Trajetoria do desenvolvimento:revisitando o passado para repensar o futuro. In:XLVI Congresso da Sociedade Brasileira de Economia, Administração e Sociologia Rural. Anais.Rio Branco: SBEASR, 2008. p. 1 - 21.

CERDAN, C.; ANDRADE, N.; SILVA, A. L. da; VIEIRA, H.; SILVA, E.; GUERROUÉ, Jean Louis Le. La recherche agricole, vecteur de dynamiques collectives des territoires ruraux: I'Indication géographique" Vales da Uva Goethe" au Brésil. Cahiers Agricultures, v. 27, n. 2, 2018.

COLLETIS, G.; PECQUEUR, B. Inscription spatiale des firmes, gouvernance des territoires et régulation d'ensemble. Journées de la proximité, v. 13, 2001.

. Révélation de ressources spécifiques et coordination située. Economie \& Institutions, p. 51-74, 2005. Disponível em: < https://ei.revues.org/900 >. Acesso em: 27 de setembro de 2017 .

CORDEIRO, W. C. A vitivinicultura em São Joaquim -SC: Uma nova atividade no município. 2006. Dissertação Programa de Pós-Graduação em Agroecossistemas Universidade Federal de Santa Catarina. Florianópolis. Disponível em: < https://repositorio.ufsc.br/bitstream/handle/123456789/89399/235989.pdf?sequenc $\mathrm{e}=1$ \&isAllowed $=y>$. Acesso em 10 de outubro de 2017 . 
CÓRDOVA, U. D. A et al. A contribuição do queijo artesanal serrano para o desenvolvimento regional e preservação dos campos de altitude do sul do Brasil. Desenvolvimento Regional em debate, v. 11, n. 3, p. 103-114, 2015. Disponível em: < https://portalseer.ufba.br/index.php/nit/article/view/12037 >. Acesso em: $10 \mathrm{de}$ outubro de 2017.

FAASC, Federação das Associações de Apicultores e Meliponicultores de Santa Catarina. Inventário da apicultura catarinense, 2016. Disponível em: < http://www.faasc.com.br/noticiasid/60>. Acesso em: 28 de setembro de 2018.

FONTANELLA, B. J. B., LUCHESI B. M. ; SAIDEL, M. G. B. ; RICAS, J. ; TURATO, E. R.; MELO, D. G. Amostragem em pesquisas qualitativas: proposta de procedimentos para constatar saturação teórica. Cadernos de Saúde Pública, v. 27, p. 388-394, 2011.

GOVERNO DO ESTADO DE SANTA CATARINA. Programa de Desenvolvimento e Redução das Desigualdades Regionais. Perfil socioeconômico da ADR São Joaquim. Disponível em: http://www.spg.sc.gov.br/visualizar-biblioteca/acoes/programa-dedesenvolvimento-e-reducao-das-desigualdades-regionais/787--106/file. Acesso em: 24 de setembro de 2017.

HIRCZAK, M. et al. From the Basket of Goods to a More General Model of Territorialized Complex Goods: Concepts, Analysis Grid and Questions. Canadian Journal of Regional Science, v. 31, n. 2, 2008.

LOSSO, F. B.; PEREIRA, R. M. F. A. O desenvolvimento da vitivinicultura e as possibilidades de implantação de roteiros enoturísticos na Região de São Joaquim (SC, Brasil). Revista Brasileira de Pesquisa em Turismo, v. 6, n. 2, p. 181-200, 2012.

MOLLARD, A.; PECQUEUR, B. De l'hypothèse au modèle du panier de biens et de services Histoire succincte d'une recherche. Economie rurale, v. 300, p. 110-114, 2007. Disponível em: < https://economierurale.revues.org/2270 >. Acesso em: 22 de setembro de 2017.

OGANAUSKAS F., V. Descentralização administrativa do estado de Santa Catarina: caracterização e resultados (2003-2015). 2016. Dissertação Programa de PósGraduação em Agroecossistemas, Universidade Federal de Santa Catarina, Florianópolis.

PECQUEUR, B. Qualité et développement territorial: I'hypothèse du panier de biens et de services territorialisés. Économie rurale, v. 261, n. 1, p. 37-49, 2001. Disponível em: < http://www.persee.fr/web/revues/home/prescript/article/ecoru_00130559_2001_num_261_1_5217 >.Acesso em: 22 de setembro de 2017.

O desenvolvimento territorial: Uma nova abordagem dos processos de desenvolvimento para as economias do sul. Raízes, v. 24, n. 1 e 2, p. 10-22, 2005. Disponível em: < 
https://desenvolvimentoareasperifericasblog.files.wordpress.com/2016/03/desenvol vimento-territorial-pecqueur.pdf >. Acesso em: 22 de setembro de 2017.

. Le tournant territorial de l'économie globale. Espaces et sociétés, n 124125, p. 17-32, 2006.

PIEPER, J. A.; CRUZ, F.T. da. Mudanças nos modos de produção de queijo serrano: uma análise a partir da perspectiva da divisão do trabalho e do lugar de produção (Changes in the modes of serrano cheese production: an analisys from the divison of labor and from the place of production). Revista GeoNordeste, n. 2, p. 25-39, 2014.

REQUIER-DESJARDINS, D. SISTEMAS AGROALIMENTARES LOCALIZADOS E QUALIFICAÇÃO: UMA RELAÇÃO COMPLEXA. Revista Internacional Interdisciplinar INTERthesis, v. 10, n. 2, p. 95-119, 2013. ISSN 18071384. Disponível em: < https://periodicos.ufsc.br/index.php/interthesis/article/download/18071384.2013v10n2p95/25917 >Acesso em: 11 de setembro de 2018.

SAKR, Mayara Rohrbacher; DALLABRIDA, Valdir Roque. Produtos de Santa Catarina com identidade territorial. Revista de Política Agrícola, v. 24, n. 3, p. 102-113, 2015.

SALOMÉ, J. A. Levantamento e fenologia de plantas apícolas do estado de Santa Catarina. Florianópolis, 2002. 112 f. Dissertação (Mestrado) - Universidade Federal de Santa Catarina, Centro de Ciências Agrárias. Programa de Pós-Graduação em Recursos Genéticos Vegetais.

SANTOS, J. S. Dilemas e desafios na valorização de produtos alimentares tradicionais no Brasil: um estudo a partir do Queijo do Serro, em Minas Gerais, e do Queijo Serrano, no Rio Grande do Sul. Pelotas: Ed. UFPEL, 2017. p. 322.

SANTOS, J. S.; Cardoso, J. H., da Cruz, F. T., dos Anjos, F. S. Dilemas e desafios para circulação de queijos artesanais no Brasil. Vigilância Sanitária em Debate:

Sociedade, Ciência \& Tecnologia, v. 4, n. 4, p. 13-22, 2016.

SÃO JOAQUIM ONLINE, Internacionalmente reconhecida, maçã fuji de São Joaquim busca identificação geográfica, São Joaquim, 2018. Disponível em: < https://saojoaquimonline.com.br/agricultura/2018/07/05/internacionalmentereconhecida-maca-fuji-de-sao-joaquim-busca-identificacao-geografica/> Acesso em: 20 de maio de 2019.

SILVA, R.; SOMMER, R. O PRODETUR-SUL e os municípios turísticos do planalto serrano catarinense. III Seminário de Pesquisa em Turismo do Mercosul. Caxias do Sul: 1-22 p. 2005.

TORESAN, L.; MATTEI, L.; GUZZATTI, T. Estudo do potencial do agroturismo em Santa Catarina: impactos e potencialidades para a agricultura familiar. Instituto Cepa/SC, 2002. 
YAMAGUCHI, C. K. O queijo artesanal serrano como fator de desenvolvimento nos campos de altitude no sul do Brasil.In: YAMAGUCHI, C. K et al. (Org.)Visão contemporânea e sustentável da Serra Catarinense. Lages: Ed. Uniplac, 2016 p. 109120.

Ademir Antonio Cazella. Graduação em Agronomia pela UFSC. Doutor em Ordenamento Territorial pelo Centre d'Etudes Supérieures d'Aménagement Tours/França. É professor titular do Programa de Pós-Graduação em Agroecossistemas da Universidade Federal de Santa Catarina (PGA/UFSC). ademir.cazella@ufsc.br

Leandro Guimarães Nunes de Paula. Graduação em Agronomia pela Universidade Federal de Uberlândia. Mestrando, na área de Desenvolvimento Rural Sustentável, pelo Programa de Pós-graduação em Agroecossistemas, na Universidade Federal de Santa Catarina (UFSC) e pesquisador do Laboratório de Estudos da Multifuncionalidade Agrícola e do Território (LEMATE). leandroguimaraesnunes@gmail.com

Monique Medeiros. Graduação em Agronomia pela Universidade Estadual Paulista "Júlio de Mesquita Filho" (Unesp). Doutora em Agroecossistemas, na área de Desenvolvimento Rural Sustentável, pela Universidade Federal de Santa Catarina (UFSC/PPGA). Professora Adjunta na Universidade Federal do Pará (UFPA), atuando junto à Faculdade de Agronomia (FAGRO) do Campus Universitário do Tocantins-Cametá, na qual também exerce a função de Coordenadora de Pesquisa e Pós-Graduação. Colaboradora no Programa de Pós Graduação em Agriculturas Amazônicas (PPGAA/UFPA).mmedeiros@ymail.com

Valério Alécio Turnes. Graduação em Agronomia pela Universidade Federal de Santa Catarina e doutorado em Engenharia de Produção pela Universidade Federal de Santa Catarina. Professor Adjunto do Centro de Ciências da Administração e Ciências Sócio-econômicas da Universidade do Estado de Santa Catarina (ESAG/UDESC).valerio.turnes@yahoo.com.br 
Como citar: CAZELLA, Ademir Antonio et al. A construção de um território de desenvolvimento rural: recursos e ativos territoriais específicos. Redes, Santa Cruz do Sul, v. 24, n. 3, p. 49-74, set. 2019. ISSN 1982-6745. Disponível em: https://doi.org/10.17058/redes.v24i3.14118.

\section{CONTRIBUIÇÃO DE CADA AUTOR}

\section{Ademir Antonio Cazella}

- Participação e análise das informações obtidas da revisão bibliográfica e das entrevistas;

- Elaboração e redação do texto do artigo, com co-apresentação de versão preliminar em evento científico (AgriUrb- Porto Alegre);

- Seleção de referências bibliográficas.

Leandro Guimarães Nunes de Paula

- Elaboração da revisão bibliográfica sobre o enfoque teórico-metodológico da Cesta de Bens e Serviços Territorais;

- Coleta de dados de campo;

- Participação e análise das informações obtidas da revisão bibliográfica e das entrevistas;

- Elaboração e redação do texto do artigo, com co-apresentação de versão preliminar em evento científico (AgriUrb- Porto Alegre);

- Seleção de referências bibliográficas.

Monique Medeiros

- Participação e análise das informações obtidas da revisão bibliográfica e das entrevistas;

- Elaboração e redação do texto do artigo, com co-apresentação de versão preliminar em evento científico (AgriUrb- Porto Alegre);

- Seleção de referências bibliográficas.

Valério Alécio Turnes

- Participação e análise das informações obtidas da revisão bibliográfica e das entrevistas;

- Elaboração e redação do texto do artigo;

- Seleção de referências bibliográficas. 